\title{
Potential Adjuvant Effects of Nigella sativa Seeds to Improve Specific Immunotherapy in Allergic Rhinitis Patients
}

\author{
Hülya Işık ${ }^{a}$ Adile Çevikbaşa Ümran Soyoğul Gürer ${ }^{a}$ Bayram Kıran ${ }^{c}$ \\ Yağız Üresin ${ }^{d}$ Pervin Rayaman ${ }^{a}$ Erkan Rayaman ${ }^{a}$ Burçak Gürbüz ${ }^{a}$ \\ Suna Büyüköztürk ${ }^{b}$ \\ ${ }^{a}$ Department of Pharmaceutical Microbiology, Faculty of Pharmacy, Marmara University, ${ }^{\text {b }}$ Department of Internal \\ Medicine, Istanbul Faculty of Medicine, Istanbul University, ' Institute of Experimental and Medical Research, \\ Istanbul University, and d Department of Pharmacology and Clinical Pharmacology, Istanbul University, Istanbul, \\ Turkey
}

\section{Key Words}

Nigella sativa $\cdot$ Phagocytosis • Intracellular killing activity •

Allergic rhinitis · Active immunotherapy

\begin{abstract}
Objective: To investigate the effects of Nigella sativa seed supplementation on symptom levels, polymorphonuclear leukocyte (PMN) functions, lymphocyte subsets and hematological parameters of allergic rhinitis. Subjects and Methods: Twenty-four patients randomly selected from an experimental group of 31 (mean age 34 years) sensitive to house dust mites with allergic rhinitis and a control group of 8 healthy volunteers (mean age 23 years) were treated with allergen-specific immunotherapy in conventional doses for 30 days. After a month of immunotherapy, 12 of the 24 patients and the 8 healthy volunteers were given $N$. sativa seed supplementation ( $2 \mathrm{~g} /$ day orally) for 30 days. The remaining 12 patients continued only on immunotherapy during the same period. The other 7 patients were given $0.1 \mathrm{ml}$ saline solution subcutaneously once a week as a placebo. The symptom scores, PMN functions, lymphocyte subsets and other hematological parameters were evaluated before and after all treatment periods. Results: There was a statistically significant increase in the phagocytic and intracellular killing ac-
\end{abstract}

tivities of PMNs of patients receiving specific immunotherapy, especially after the addition of $N$. sativa seed. The CD8 counts of patients receiving specific immunotherapy plus $N$. sativa seed supplementation significantly increased compared to patients receiving only specific immunotherapy. PMN functions of healthy volunteers significantly increased after $N$. sativa seed supplementation compared to baseline. Conclusion: $N$. sativa seed supplementation during specific immunotherapy of allergic rhinitis may be considered a potential adjuvant therapy.

Copyright $\odot 2010$ S. Karger AG, Basel

\section{Introduction}

Linn. Nigella sativa, also known as black seed or black cumin, is a member of the Ranunculaceae family, an annual herbaceous plant that grows in countries bordering the Mediterranean sea, Pakistan and India [1]. It has been used as a natural remedy in many Middle Eastern countries for over 2,000 years. It is a traditional folk medicine used for a wide range of illnesses, such as bronchial asthma, headache, dysentery, infections, obesity, back pain, hypertension, dermatological and gastrointestinal problems $[2,3]$.

\section{KARGER}

Fax +4161306 1234

E-Mail karger@karger.ch

www.karger.com
(C) 2010 S. Karger AG, Basel

1011-7571/10/0193-0206\$26.00/0

Accessible online at:

www.karger.com/mpp
Ümran Soyoğul Gürer

Department of Pharmaceutical Microbiology, Faculty of Pharmacy University of Marmara, Haydarpasa, TR-34668 Istanbul (Turkey)

Tel. +90 21641429 62/101, Fax +90 2163452952

E-Mail umran.gurer@superonline.com 
Fig. 1. Diagram of the study design. Symptom scores (X), PMN functions, lymphocyte subsets and other hematological parameters were evaluated. $\mathrm{AR}=$ Allergic rhinitis.

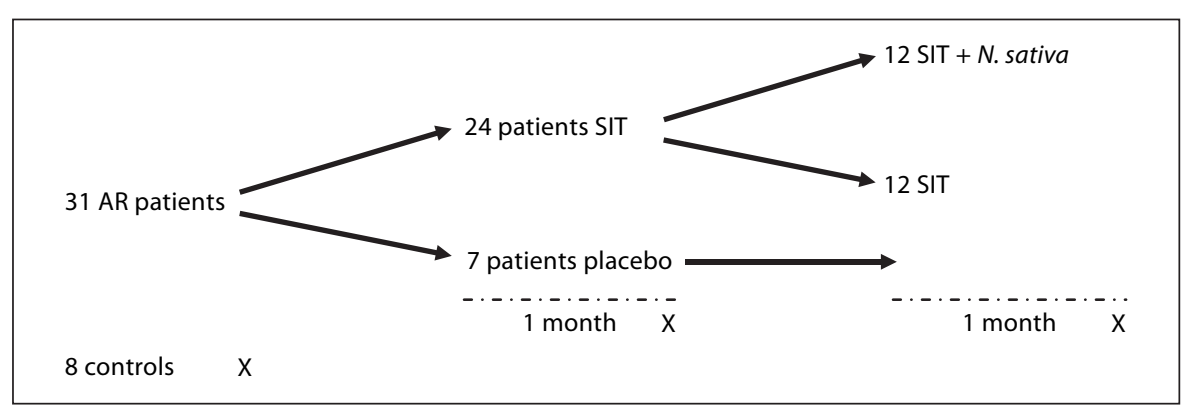

$N$. sativa seed is commonly eaten alone or in combination with honey and in many food preparations [4]. Black cumin seeds are of importance as a carminative and spice, as they are often used as a condiment in bread and other dishes [5]. Black seed contains more than 100 valuable nutrients, approximately including protein: $21 \%$, carbohydrates: $38 \%$ and plant fats and oils (fixed oil and volatile oil): $35 \%$. The active ingredients of black seed are thymoquinone, nigellone and fixed oils. Other ingredients include linoleic acid, oleic acid, calcium, potassium, iron, zinc, magnesium, selenium, vitamin $A$, vitamin $B$, vitamin $B_{2}$, niacin, vitamin $C$ and essential oil, and monosaccharides in the form of glucose, rhamnose, xylose and arabinose $[2,4,5]$.

Several studies have focused on an explanation of the mechanism of the beneficial effects of $N$. sativa. In relatively low concentrations, nigellone, the carbonyl polymer of thymoquinone, has been found to be effective in inhibiting histamine release from mast cells in vitro [4]. $N$. sativa oil has been demonstrated to modify leukotriene synthesis and inhibit histamine release [3]. It has been shown that $N$. sativa increased the proliferative response of spleen cells to allogenic cells and their IL-3 production [6].

N. sativa seed constituents possess potential immunomodulatory effects and are reported to have antibacterial, antifungal, antihelminthic and antiviral properties. For instance, $N$. sativa seed extracts and thymoquinone have shown potential protective effects against Schistosoma mansoni infections, and antibacterial activity against several bacterial strains including Escherichia coli, Bacillus subtilis, Streptococcus faecalis, Staphylococcus aureus and Pseudomonas aeruginosa as well as against the pathogenic yeast Candida albicans and fungus [4].

The mechanism of action of N. sativa on allergic diseases is still unclear. Büyüköztürk et al. [7] demonstrated that N. sativa oil had no effects on Th1 and Th2 cytokine production of splenic mononuclear cells in mice. How- ever, other studies have shown that it affects Th2 cytokine production in the lung [8-10]. The main active constituent, thymoquinone, has been found to attenuate allergic inflammation by inhibiting Th2 cytokines and eosinophil infiltration in the airways. On the other hand, there is no sufficient study related to the clinical benefits of black seed on the symptoms of allergic patients. Recently, Kalus et al. [11] have shown that the oil of N. sativa was effective in relieving symptoms of allergic diseases. In the present study, we have assessed the effects of $N$. sativa seed supplementation on symptom levels, peripheral blood polymorphonuclear leukocyte (PMN) functions (phagocytic and intracellular killing activity) and lymphocyte subsets in patients with allergic rhinitis.

\section{Subjects and Methods}

\section{Subjects}

Thirty-one patients (mean age 34 years) with allergic rhinitis sensitive only to house dust mites were enrolled in the experimental group. Exclusion criteria were the existence of an infectious, rheumatic, malignant or any other systemic disease and detection of a seasonal allergen sensitivity. The control group consisted of 8 healthy volunteers (mean age 23 years). The diagnosis of allergic rhinitis was based on history, physical examination and skin prick tests.

Treatment with Specific Immunotherapy and N. sativa Seed Supplementation

After diagnosis of house dust mite sensitivity, 24 patients from the experimental group were randomly selected to begin treatment with subcutaneous allergen-specific immunotherapy (SIT, Alutard D. pteronyssinus + D. farinea, ALK-Abello, Denmark) using the conventional doses [12] (fig. 1). After a month of immunotherapy, 12 of them and all the healthy volunteers were given $N$. sativa seed supplementation ( $2 \mathrm{~g} /$ day orally) for 30 days. The remaining 12 patients continued to take immunotherapy only during seed supplementation. A third group of patients $(n=7)$ were given $0.1 \mathrm{ml}$ saline solution subcutaneously once a week as a placebo for 2 months (fig. 1). N. sativa (L.) (MARE 9025) was authenticated by Dr. Ertan Tuzlac1, Department of Pharmaceutical 
Table 1. Comparison of lymphocyte subsets in different stages of the study

\begin{tabular}{|c|c|c|c|c|c|}
\hline \multirow[t]{2}{*}{ Therapy } & \multicolumn{5}{|c|}{ Lymphocyte subsets } \\
\hline & CD3 & CD19 & $\mathrm{CD} 4$ & CD8 & CD16/56 (NK) \\
\hline Before SIT & $70.64 \pm 8.82$ & $12.18 \pm 4.85$ & $40.45 \pm 10.96$ & $31.36 \pm 6.93$ & $20.00 \pm 11.65$ \\
\hline After 1st month of SIT & $68.45 \pm 10.49$ & $11.09 \pm 5.64$ & $42.64 \pm 6.48$ & $26.73 \pm 6.3^{*}$ & $13.91 \pm 5.82$ \\
\hline \multicolumn{6}{|l|}{ After SIT + N. sativa seed } \\
\hline supplementation (30 days) & $70.36 \pm 9.43$ & $11.18 \pm 7.06$ & $40.91 \pm 7.14$ & $30.55 \pm 5.6^{*}$ & $13.00 \pm 5.36$ \\
\hline After 2nd month of SIT & $76.00 \pm 3.36$ & $7.42 \pm 2.50$ & $43.71 \pm 7.8$ & $31.00 \pm 6.87$ & $9.85 \pm 2.79$ \\
\hline
\end{tabular}

Results are expressed as mean \pm SD. ANOVA and Student-Newman-Keuls test were performed on the results (repeated measures of ANOVA and Student-Newman-Keuls Multiple comparison test). ${ }^{*} \mathrm{p}<0.05$.

Botany, Faculty of Pharmacy, University of Marmara, Istanbul, Turkey. This study was approved by the Ethics Committee, Istanbul Faculty of Medicine, Istanbul University, Turkey.

\section{Measurement of Allergic Rhinitis Symptoms}

Patients were asked to rate their symptom levels on a visual analog scale (VAS, $0=$ no symptoms, $10=$ worst symptoms) at the first visit after the first month of SIT and after the SIT $+N$. sativa supplementation placebo or at the end of the second month of SIT.

\section{Isolation of PMNs}

Peripheral blood samples $(10 \mathrm{ml})$ from patients with allergic rhinitis and healthy volunteers were drawn with ethylenediaminetetraacetic acid (EDTA). PMNs from venous blood with EDTA $\left(1 \times 10^{7}\right.$ cells $\left./ \mathrm{ml}\right)$ were isolated by the Ficoll-Hypaque gradient centrifugation method previously described [13].

\section{Measurement of PMN Activities}

Phagocytosis and intracellular killing activity were assayed by modifying the method of Alexander et al. [14]. In the modified method, Ficoll was used instead of dextran and PMNs were counted by microscope instead of using the standard pour plate technique. PMN viability was assayed as $98 \%$ by trypan blue staining. PMNs were suspended in Hanks' buffered salt solution (HBSS) and cell density was adjusted by dilution $\left(1 \times 10^{7}\right.$ cell $\left./ \mathrm{ml}\right)[15-$ 17].

A clinical strain of C. albicans was used in order to determine the phagocytic and intracellular killing activities of PMNs. C. albicans viability was assayed as greater than $98 \%$ by methylene blue staining. PMNs were suspended in HBSS and incubated at $37^{\circ} \mathrm{C}$ for $30 \mathrm{~min}$ in a shaking incubator. In a separate tube, C. albicans was suspended in HBSS and then an aliquot of sterile human serum (1:4) was added to induce opsonization and the mixture was incubated at $37^{\circ} \mathrm{C}$ for $30 \mathrm{~min}$. Subsequently, opsonized yeast cells were added to the PMN tube. The final mixture contained $5 \times$ $10^{6} \mathrm{PMNs} / \mathrm{ml}$ and $5 \times 10^{6}$ yeasts $/ \mathrm{ml}$. Dead yeast cells were determined by adding $0.01 \%$ methylene blue stain (1:1 ratio) in the last 5 min of the incubation. The phagocytic activity was determined by the percentage of PMNs that had phagocytosed yeast cells. Intracellular killing activity was determined by the percentage of PMNs that included killed yeast cells $[15,17,18]$.

\section{Immunomonitoring by Flow Cytometry}

Patient immune profiles were determined by analyzing blood samples, whole blood lysis on flow cytometry (Becton Dickinson FACSCalibur) following heparinization and treating with monoclonal antibodies (CD3, CD4, CD8, CD19, CD16/56-NK). Ten thousand cells were counted in the appropriate lymphocyte gate for each tube's sample in flow cytometry and then the percentage values of all markers were determined by using CellQuest software program.

\section{Statistics}

The data were analyzed using ANOVA and paired StudentNewman-Keuls multiple comparison test.

\section{Results}

There were no significant differences between study groups in terms of lymphocyte subsets, except the CD8 counts that showed a significant decrease when analyzed after the first month of SIT (table $1, \mathrm{p}<0.05$ ). The number of CD8 T cells after SIT recovered when SIT patients received a 1-month supplementation with $N$. sativa seeds. The PMN functions for different treatment modalities and periods are given in table 2. Phagocytic and intracellular killing activities of patients who received SIT for 1 month and SIT plus N. sativa seed supplementation for 30 days showed significant increases compared to phagocytic and intracellular killing activities before SIT ( $\mathrm{p}<$ $0.001, \mathrm{p}<0.01$ ). Phagocytic and intracellular killing activities of PMNs of the same patients who received SIT plus $N$. sativa seed supplementation for 30 days also showed significant increases compared to those after 1 month of SIT (table 2, $\mathrm{p}=0.002, \mathrm{p}=0.05$ ). However, PMN activities of those patients who were given only SIT were not different at the end of the second month compared to the results obtained after the first month of SIT ( $p>0.05)$. 
Table 2. Comparison of PMN functions in different periods of the study

\begin{tabular}{|c|c|c|}
\hline \multirow[t]{2}{*}{ Therapy periods } & \multicolumn{2}{|l|}{ PMN functions } \\
\hline & $\begin{array}{l}\text { phagocytosis, } \\
\%\end{array}$ & $\begin{array}{l}\text { intracellular } \\
\text { killing } \\
\text { activity, \% }\end{array}$ \\
\hline Before SIT $(n=31)$ & $40.17 \pm 9.80^{\mathrm{a}}$ & $1.75 \pm 1.54^{\mathrm{b}}$ \\
\hline After 1st month of SIT $(n=24)$ & $57.67 \pm 15.13^{\mathrm{c}}$ & $3.00 \pm 2.00^{\mathrm{d}}$ \\
\hline $\begin{array}{l}\text { After SIT + N. sativa seed supple- } \\
\text { mentation }(30 \text { days })(n=12)\end{array}$ & $70.50 \pm 8.17^{\mathrm{e}}$ & $4.84 \pm 2.27^{\mathrm{f}}$ \\
\hline After 2 nd month of SIT only $(n=12)$ & $53.28 \pm 4.38^{\mathrm{g}}$ & $1.71 \pm 1.88^{\mathrm{h}}$ \\
\hline Placebo (saline solution) $(n=7)$ & $36.85 \pm 11.58^{\mathrm{i}}$ & $1.00 \pm 0.81^{j}$ \\
\hline
\end{tabular}

Results are expressed as means \pm SD. ANOVA and StudentNewman-Keuls test were performed on the results (repeated measures of ANOVA and Student-Newman-Keuls multiple comparisons test). ${ }^{*} \mathrm{p}<0.05$. $\mathrm{p}^{\text {(c vs. a) }}<0.0001, \mathrm{p}^{\text {(d vs. b) }}=0.01, \mathrm{p}^{(\mathrm{e} \text { vs. c) }}=0.002$, $\mathrm{p}^{(\mathrm{f} \text { vs. } \mathrm{d})}=0.05, \mathrm{p}^{(\mathrm{e} \text { vs. g })}=0.002, \mathrm{p}^{(\mathrm{f} \text { vs. } \mathrm{h})}<0.001, \mathrm{p}^{(\mathrm{evs} . \mathrm{i})}<0.0001$, $\mathrm{p}^{(\mathrm{f} \text { vs. j) }}=0.0003$.

Phagocytic and intracellular killing activities of PMNs of the same patients who received SIT plus N. sativa seed supplementation for 30 days also showed significant increases compared to those after 2 months of SIT (table 2, $\mathrm{p}=0.002, \mathrm{p}<0.001)$. PMN phagocytic and intracellular killing activities of patients receiving placebo were significantly lower compared to patients who received either SIT or SIT $+N$. sativa seed supplementation $(\mathrm{p}<0.0001$, $\mathrm{p}=0.0003$ ). PMN functions of healthy young volunteers significantly increased after $N$. sativa seed supplementation compared to those before supplementation (table 3, $\mathrm{p}<0.001, \mathrm{p}<0.01)$.

According to the one-way ANOVA test, power analysis test was done and power was found as $(1-\beta)=0.9298$ for phagocytosis and $(1-\beta)=0.8426$ for intracellular killing activity when $\alpha=0.05$.

\section{Discussion}

This study demonstrated that $N$. sativa supplementation has beneficial effects on the symptoms of patients with allergic rhinitis. These results confirmed the findings obtained by Kalus et al. [11], who showed the efficacy of orally given $N$. sativa oil in allergic rhinitis, bronchial asthma and atopic dermatitis. From this point of view, $N$. sativa may be considered an appropriate 'adjuvant' for the therapy of allergic diseases. It is well known
Table 3. PMN functions of healthy young volunteers before and after $N$. sativa seed supplementation $(\mathrm{n}=8)$

\begin{tabular}{|c|c|c|}
\hline \multirow{2}{*}{$\begin{array}{l}\text { N. sativa seed supplemen- } \\
\text { tation ( } 2 \text { g/day for } 30 \text { days } \\
\text { orally) }\end{array}$} & \multicolumn{2}{|l|}{ PMN functions } \\
\hline & $\begin{array}{l}\text { phagocytosis, } \\
\%\end{array}$ & $\begin{array}{l}\text { intracellular } \\
\text { killing activity, \% }\end{array}$ \\
\hline Before supplementation & $43.88 \pm 10.41$ & $1.25 \pm 1.38$ \\
\hline After supplementation & $69.13 \pm 8.91^{* *}$ & $3.62 \pm 2.20^{*}$ \\
\hline
\end{tabular}

Results are expressed as means \pm SD. Paired t test was performed on the results. ${ }^{*} \mathrm{p}<0.01,{ }^{* *} \mathrm{p}<0.001$.

that SIT, which depends on the administration of increasing doses of allergen extracts, is the only specific and curative approach for the treatment of IgE-mediated allergy. In recent years, adjuvant therapies have been investigated in order to increase the efficacy of SIT in the therapy of allergic diseases. Mycobacterium vaccae, lipopolysaccharide, Lactobacillus spp. and oral bacterial extracts have been examined for their adjuvant effects [19].

The beneficial effects of $N$. sativa seed supplementation on the symptoms of allergic rhinitis may be due to its antihistaminic properties. Chakravarty [3] demonstrated that when rat macrophages were incubated with nigellone thymoquinone (carbon polymer) obtained from $N$. sativa seed, nigellone inhibited histamine release from macrophages, intracellular calcium release, protein kinase $\mathrm{C}$ activation and oxidative energy metabolism [3]. Preclinical [1, 6] and clinical [2] studies have also shown antihistaminic effects of $N$. sativa seed using a gastric ulcer model induced by oral administration of ethanol, which caused a significant increase in mucosal histamine content. In rats pretreated with $N$. sativa oil before ulcer induction, gastric mucosal histamine content significantly decreased compared with the nonpretreated group [1]. Another study showed that N. sativa oil inhibits the COX and 5-lipoxygenase pathways of arachidonic acid metabolism and decreases the synthesis of thromboxane and leukotrienes [16]. Since leukotrienes are potent mediators of asthma and histamine plays an important role in immediate hypersensitivity reactions, the above findings might explain the mechanism mediating the efficacy of $N$. sativa on allergic diseases and asthma. When nigellone was administered to children and adults during the treatment of bronchial asthma, $N$. sativa oil decreased the IgE level, eosinophil count 
and endogenous cortisol in plasma and urine [2], indicating the effectiveness of $N$. sativa oil and seeds as an adjuvant for the treatment of allergic diseases. Also no sign of toxicity was observed.

In our study the PMN functions of patients who received SIT plus N. sativa seed supplementation increased compared to those taking only SIT or placebo. As is seen in the Results section, the power analysis is in accordance with the $\mathrm{p}$ values that have been determined by repeated measures of ANOVA and Student-Newman-Keuls multiple comparisons test shown in table 2 .

Currently, only one study has explored the effects of $N$ sativa on the leukocyte phagocytic activity of PMNs in vitro. In that study, no effect of N. sativa or its fractions was noticed on the phagocytic or killing activities of PMNs in the presence of $S$. aureus bacteria. On the other hand, N. sativa seed supplementation with specific immunotherapy increased CD8 cell count, which was decreased after the 1st month of specific immunotherapy. The mechanism of $N$. sativa stimulation of the increase in PMN functions and CD8 cells is unclear. Haq et al. [6] demonstrated that $N$. sativa seeds activated T lymphocytes to secrete IL- 3 and to cause enhanced IL- $1 \beta$ production. In a later study, the same authors had fractionated $N$ sativa proteins by ion exchange chromatography and showed that some proteins have suppressive and other stimulatory properties in lymphocyte cultures [20]. It may be speculated that an important number of cytokines induced by N. sativa produce immunomodulatory changes.

The augmented PMN function by N. sativa seed supplementation can explain the beneficial effect of this sup- plementation on allergic rhinitis patients. The results of this study showed that $N$. sativa also increased the PMN functions in healthy controls, indicating that this effect is not specific to allergic patients. Although there is no confirmed evidence that allergic rhinitis patients are more susceptible to upper respiratory tract infections than normal, it has been observed that such infections lead to symptom aggravation in rhinitis patients, last longer and tend to become chronic. From this point of view, it can be speculated that augmented PMN functions stimulated by $N$. sativa supplementation may improve the response to microorganisms in rhinitis patients.

\section{Conclusion}

Our findings suggest that $N$. sativa seed supplementation may have beneficial immunomodulatory and antiallergic effects on allergic patients and healthy subjects as well. Our results show that $N$. sativa seed supplementation together with SIT seem to achieve better clinical recovery of the suppressed immune system of allergic patients. The potential role of $N$. sativa as an adjuvant therapy in patients treated with SIT should be further studied and clarified.

\section{Acknowledgments}

The authors are thankful to the Marmara University Research Foundation and Prof. Dr. Ertan Tuzlaci for the identification of the plant specimen of the studied material.

\section{References}

1 El-Dakhakhny M, Barakat M, El-Halim MA, Aly SM: Effect of N. sativa oil on gastric secretion and ethanol induced ulcer in rats. J Ethnopharmacol 2000;72:299-302.

$\checkmark 2$ Salem ML: Immunomodulatory and immunotherapeutic properties of the Nigella sativa L. seed. Int Immunopharmacol 2005;5: 1749-1770.

3 Chakravarty N: Inhibition of histamin release from mast cells by nigellone. Ann Allergy 1993;70:237-242.

4 Swamy SMK, Tan BKH: Cytotoxic and immunopotentiating effects of ethanolic extract of Nigella sativa L. seeds. J Ethnopharmacol 2000;70:1-7.

5 Burits M, Bucar F: Antioxidant activity of Nigella sativa essential oil. Phytother Res 2000;14:323-328.
Haq A, Abdullatif M, Lobo IP, Khabar SAK, Sheth UK, Al-Sedairy TS: Nigella sativa: effect on human lymphocytes and polymorphonuclear leucocyte phagocytic activity. Immunopharmacology 1995;30:147-155.

-7 Büyüköztürk S, Gelincik A, Ozșeker F, Genç S, Savran FO, Kiran B, Yillar G, Erden S, Aydin F, Colakoğlu B, Dal M, Ozer H, Bilir A: Nigella sativa (black seed) oil does not affect the T-helper 1 and T-helper 2 type cytokine production from splenic mononuclear cells in allergen sensitized mice. J Ethnopharmacol 2005; 100:295-298.
8 Abbas AT, Abdel-Aziz MM, Zalata KR, Abd Al-Galel Tel-D: Effect of dexamethasone and Nigella sativa on peripheral blood eosinophil count, IgG1 and IgG2a, cytokine profiles and lung inflammation in murine model of allergic asthma. Egypt J Immunol 2005;12: 95-102.

\$ El Gazzar M, El Mezayen R, Marecki JC, Nicolls MR, Canastar A, Dreskin SC: Antiinflammatory effect of thymoquinone in a mouse model of allergic lung inflammation. Int Immunopharmacol 2006;6:1135-1142.

10 El Mezayen R, El Gazzar M, Nicolls MR, Marecki JC, Dreskin SC, Nomiyama H: Effect of thymoquinone on cyclooxygenase expression and prostaglandin production in a mouse model of allergic airway inflammation. Immunol Lett 2006;106:72-81. 
11 Kalus U, Pruss A, Bystron J, Jurecka M, Smekalova A, Lichius JJ, Kiesewetter H: Effect of Nigella sativa (black seed) on subjective feeling in patients with allergic diseases. Phytother Res 2003;17:1209-1214.

12 Bousquet J, Lockey RF, Malling HJ (eds): WHO position paper. Allergen immunotherapy: therapeutic vaccines for allergic diseases. Allergy 1998;53(suppl 44):1-42.

13 Boyum A: Isolation of molecular cells and granulocyte from human blood: isolation of mononuclear cells by one centrifugation and granulocyte by combining centrifugation and sedimentation at $1 \mathrm{~g}$. Scand J Clin Lab Invest 1968;97:77-89.

- 14 Alexander JW, Windhorst DB, Good RA: Improved tests for the evolution of neutrophil function in human disease. J Lab Clin Med 1968;72:136-148.
15 Barbior BM, Cohen HJ: Measurement of neutrophil function: phagocytosis, degranulation, the respiratory burst and bacterial killing; in Cline MJ (ed): Methods in Hematology, Leukocyte Function, ed 1. New York, Churchill Livingstone, 1981, pp 1-38.

16 Gocer P, Gurer SU, Erten N, Palanduz S, Rayaman E, Akarsu B, Karan A, Cevikbas A: Comparison of polymorphonuclear leukocyte functions in elderly patients and healthy young volunteers. Med Princ Pract 2005; 14: 382-385.

17 Richardson MD, Scott G., Shankland GS: Effect of cilofungin on phagocytosis and intracellular killing of Candida albicans by human neutrophils. Eur J Clin Microbiol Infect Dis 1992;11:22-26.
18 Gurer SU, Gocer P, Ercag E, Erten N, Rayaman E, Gurbuz B, Uzer A, Karan A, Cevikbas A: The effects of some antibiotics on polymorphonuclear leukocyte functions of elderly patients in vitro before and after zinc supplementation. Int Immunopharmacol 2006;5:808-816.

19 Matricardi PM, Bonini S: Mimicking microbial 'education' of the immune system: a strategy to revert the epidemic trend of atopy and allergic asthma? Respir Res 2000;1:129132.

20 Haq A, Lobo IP, Al-Tufail M, Rama RN, Al Sedairy TS: Immunomodulatory effect of Nigella sativa proteins fractionated by ion exchange chromatography. Int J Immunopharmacol 1999;21:283-295. 